\title{
CASE REPORT OF ISOLATED HEPATIC TUBERCULOSIS
}

\author{
MOHAMMAD RAFIQUL ISLAM ${ }^{1}$, MARIA MAKSUD ${ }^{2}$, PRIANKA BARAL ${ }^{3}$, MAHBUB HOSSAIN ${ }^{4}$, AHMEDUL KABIR $^{5}$
}

\begin{abstract}
Tuberculosis is one of the most common diseases in Bangladesh and has variable clinical manifestations. Isolated Hepatic tuberculosis is not a common disease; in fact the presentation of hepatic tuberculosis may be without having history of any active Pulmonary TB or military TB. Patient usually present without having any typical symptoms; so it is difficult for a physician to diagnose the disease quickly. Patient presenting with space occupying lesion in liver is confused with abscess, hepatoma or metastases. Here we are presenting a case report of isolated hepatic tuberculosis.
\end{abstract}

Received: 02 February 2014

Accepted: 19 December 2014

\section{Introduction}

As isolated hepatic tuberculosis is a rare condition and liver involvement is clinically silent; initially it is difficult to find the cause of presenting complaints. The nomenclature of hepatic tuberculosis is confusing. Multiple terms like tubercular hepatitis, local tuberculosis, secondary tuberculosis, isolated tuberculosis, and atypical tuberculosis have been used by various authors and the same term may have a different connotation when used by different authors. ${ }^{1,2}$

Broadly speaking, hepatic tuberculosis presents in three forms. The most common form is the diffuse hepatic involvement, seen along with pulmonary or military tuberculosis in $50-80 \%$ of patients dying of pulmonary tuberculosis. Despite the diffuse involvement of the liver pathologically, symptoms of liver disease are absent. The second form is diffuse hepatic infiltration with small granulomas (less than $2 \mathrm{~mm}$ ) without recognizable pulmonary involvement (granulomatous liver disease). The third much rarer form presents as a focal/local tuberculoma or abscess. ${ }^{3}$ Isolated hepatic tuberculoma (synonyms nodular hepatic tuberculosis, macronodular hepatic tuberculosis) is perhaps the rarest form of local hepatic tuberculosis. ${ }^{4}$

\section{Case Presentation}

A 21 year old male patient came with right hypochondriac pain and nausea for last 6 months.
Pain was constant, dull aching, no radiation and no aggravating factor but relieved with non steroidal anti inflammatory drugs. There was nausea but no vomiting. He had no history of yellow coloration of sclera, mucous membrane, skin and urine. There was weight loss of about $3 \mathrm{~kg}$ in last 6 months. He had no history of feve. There was no history of tuberculosis or any contact with tuberculosis patient. His personal history was unremarkable. General examination and systemic examination were unremarkable other than mild tenderness in right hypochondriac region.

Laboratory data revealed normal serum $\mathrm{Hb} 13.6 \mathrm{gm} /$ dl, ESR $80 \mathrm{~mm}$ in first hour, white blood cell count $11000 / \mathrm{Cmm}$, differential count polymorph $60 \%$, lymphocyte $20 \%$, eosinophil $14 \%$, monocyte $6 \%$, circulating eosinophil $1540 / \mathrm{Cmm}$. Chest X ray posterior anterior view was normal. USG of whole abdomen revealed normal size liver with small hypoechoic focal lesion in the anterior inferior and lateral segment of left lobe, measuring $1.7 \times 1.1 \mathrm{~cm}$. Rest of the liver parenchyma appears normal. Features suggestive of space occupying lesion. Liver function tests were normal. Computed Tomography (CT) of upper abdomen pre and post contrast revealed liver is mildly enlarged. Multiple small rims enhanced well defined rounded hypodense areas are seen in the hepatic parenchyma. (Fig 1)At 06 minute delayed post contrast scan, most of the hypodense areas became isodense to hepatic parenchyma. Possibilities are a) Infllamatory lesions/micro abscess b) Atypical hemangioma c) Secondaries.

1. Assistant Professor, Department of Medicine, Dhaka Medical College.

2. Honorary Medical office, Department of Medicine, Dhaka Medical College.

3. Honorary Medical office, Department of Medicine, Dhaka Medical College.

4. Indoor Medical officer, Department of Medicine, Dhaka Medical College.

5. Associate Professor, Department of Medicine, Dhaka Medical College.

Address of Correspondence: Mohammad Rafiqul Islam. Assistant professor, Department of medicine, Room503, Dhaka Medical College Hospital-2, Dhaka. Email-drrafiq73@yahoo.com. Cell- 01753199796.

Bangladesh J Medicine 2015; 26 : 43-45 


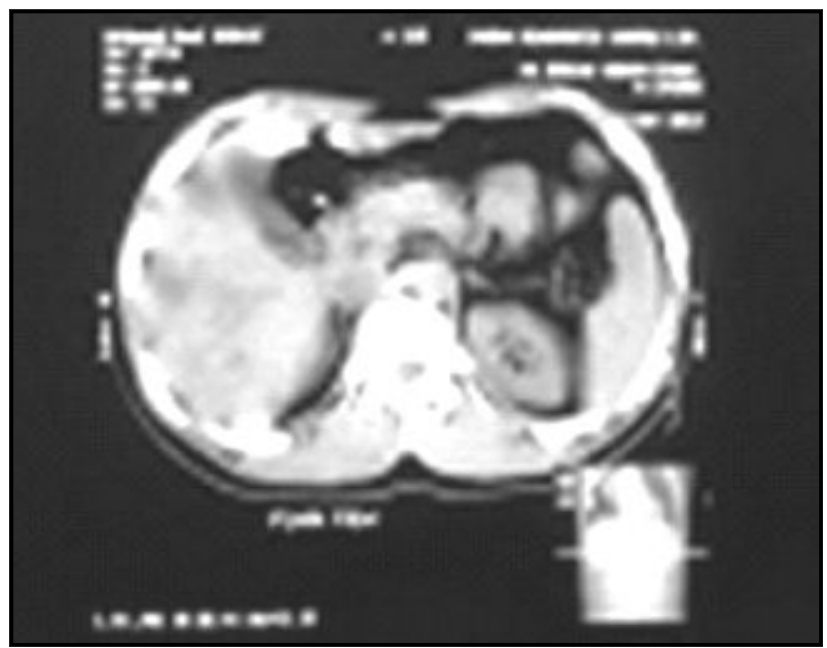

Fig.-1: CT scan of abdomen showing Hypodense liver shadow

FNAC (Fine needle aspiration cytology) done from liver mass (USG guided) revealed clusters of epithelioid cells, many lymphocytes, some histiocytes and clusters of normal hepatocytes. Background shows blood and small amount of caseous necrotic material. No malignant cell seen. Diagnosis: Granulomatous inflammation, suggestive of tuberculosis. (Fig.-2).

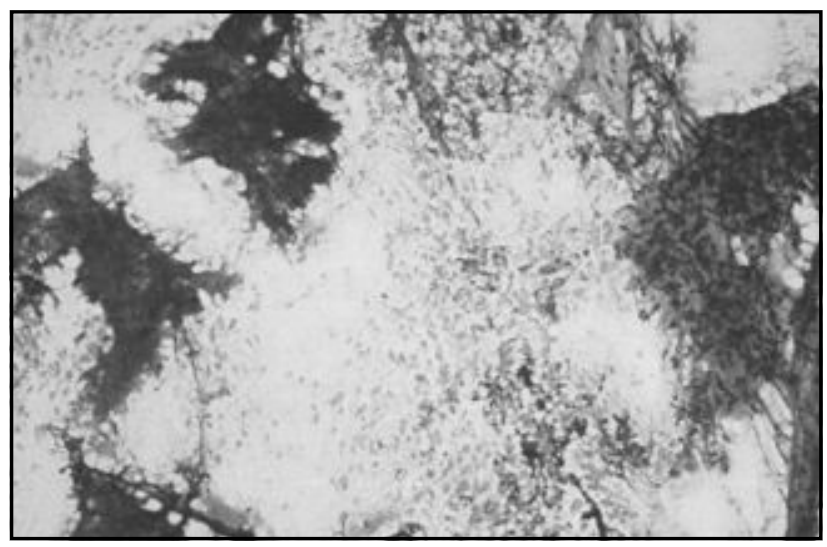

Fig.-2: FNAA revealed caseous necrosis with epitheloid cell

After getting Category-1 Anti TB regimen for two months, patient came for follow up with repeat ultrasound scan report. Patient's general condition was improved and there were no right hypochondriac pain. There were no space occupying lesions in the liver on USG scan. We started continuation phase.

\section{Discussion}

Bangladesh is an endemic zone for tuberculosis. Tubercle bacilli reach the liver by way of hematogenous dissemination : the portal of entry in the case of miliary tuberculosis is through the hepatic artery; whereas, in the case of focal liver tuberculosis, it is via the portal vein. Irrespective of the mode of entry, the liver responds by granuloma formation. Tuberculous granulomata are most frequently found in the periportal areas (zone 1 of Rappaport) but may occasionally occur in zone $3 .^{5}$

Constitutional symptoms in the form of fever, anorexia and weight loss were present in $55 \%-90 \%$ of the patients. Our patient had significant weight loss of 3 $\mathrm{Kg}$ in 6 month. Abdominal pain is present in 65\%$87 \%$ of patients ${ }^{6,7}$ but jaundice is uncommon. Our patent had right hypochondriac pain for 6 months. Hepatomegaly and splenomegaly are the commonest findings, being present in $70 \%-96 \%$ and $25 \%-55 \%$ of patients respectively ${ }^{8,9}$. Our patient had mild hepatomegaly that was observed on CT scan of abdomen.

Usually liver function tests are within normal limit. MRI and $\mathrm{CT}$ findings of liver tuberculosis reveal different stages of disease, varying from granulomatous tubercles with or without caseation necrosis to fibrosis and calcification in the healing stage $^{10}$. USG findings of hepatic tuberculosis usually show hypoechoic lesion ${ }^{11}$. In our case USG revealed hypoechoic lesion but CT scan pre contrast revealed hypoechoic but post contrast revealed isodense lesion. So it's quite difficult to find for a radiologist to reach a confirm diagnosis. Histopathological examination of the specimens from lesions is essential for exact diagnosis. FNAC for histopathology, in our case, revealed granulomatous inflammation with caseous necrotic material.

Infectious and non-infectious diseases which can cause caseating or non-caseating hepatic granulomatous such as leprosy, sarcoidosis, Hodgkin's disease, brucellosis, infectious mononucleosis, inflammatory bowel disease, drug-induced liver damage and syphilis should be considered in the differential diagnosis of hepatic tuberculosis. Chronic active hepatitis may also mimic tuberculosis of the liver ${ }^{12}$.

Hepatic tuberculosis is treated like any other extrapulmonary tuberculosis lesion. Chemotherapy with standard anti-tuberculosis drugs remains the corner stone of treatment. This is true for both diffuse as well as the local forms of the disease $\mathrm{e}^{9}$

\section{Conclusion:}

Although isolated hepatic tuberculosis is a very rare entity, still in a tuberculosis endemic country like Bangladesh, we should keep in mind that there are many facets of presentation of Tuberculosis. Clinically 
may mimic like hepatic abscess but histopathology is key to reach the diagnosis.

Conflict of Interest: Not declared.

\section{Referrences:}

1. Chen HC, Chao YC, Shyu RY, Hsieh TY. Isolated tuberculous liver abscesses with multiple hyperechoic masses on ultrasound: a case report and review of the literature. Liver Int 2003; 23: 346-50.

2. Johri BS, Kane MP, Mudbhatkal NS. Isolated tuberculosis of the liver. Indian J Med Sci 1970; 24:15-21.

3. Singbeil BA, Bickford AA, Stoltz JH. Isolation of Mycobacterium avium from ringneck pheasants (Phasianus colchicus). Avian Dis 1993; 37:612-5

4. Lim EJ, Johnson PD, Crowley P, Gow PJ. Granulomatous hepatitis: tuberculosis or not? Med J Aust 2008; 188:166-7

5. Reynolds, TB, Campra, JL, Peters RL. 'Hepatic granulomata'. In: Zakim D, Boyer T.D. (eds.) Hepatology - A textbook of liver disease, 2nd ed. W.B. Saunders: Philadelphia; 1990: 1098.
6. Oliva A,Duarte B, Jonasson O, Nadimpalli V. The nodular form of local hepatic tuberculosis. J. Clin. Gastroenterol 1990; 12: 166.

7. Hersch, C. Tuberculosis of the liver. South Afr. Med. J 1964; 38: 857 .

8. Alvarez S.Z, Carpio R. Hepatobiliary tuberculosis. Dig. Dis. Sci1983;28:193.

9. Maharaj B, Leary WP, Pudifin D.J. A prospective study of hepatic tuberculosis in 41 black patients. Quart. J. Med1987;63:517.

10. Kawamori Y, Matsui O, Kitagawa K, Kadoya M, Takashima T, Yamahana T. Macronodular tuberculoma of the liver: CT and MR findings. Am J Roentgenol 1992; 158:311-313.

11. Jain R, Sawhney S, Gupta RG, Acharya S. Sonographic appearances and percutaneous management of primary tuberculous liver abscess. J Clin Ultrasound 1998;27:159-163.

12. Rangabashyam N. Oxford Textbook of Surgery. vol II. Oxford: Oxford University Press; 1994. Abdominal Tuberculosis; 2491. 